\title{
O Processo de Formação das Representações Sociais de Competência dos Profissionais de uma Instituição Federal de Ensino
}

The Process of Formation of Social Representations of Competence of the Professionals of a federal teaching institution.

El Proceso de Formación de Representaciones Sociales de Competencia de los Profesionales de una Institución Federal de Enseñanza

Pablo Augusto Panêtto de Morais

Mestrado em Administração / Universidade Federal do Espírito Santo Instituto Federal de Brasília / Professor http://lattes.cnpq.br/8770022191354210 https://orcid.org/0000-0002-4358-2798

pablopanetto@gmail.com

Priscilla de Oliveira Martins-Silva Doutorado em Psicologia / Universidade Federal do Espírito Santo Universidade Federal do Espírito Santo / Professora http://lattes.cnpq.br/7158091678487373 https://orcid.org/0000-0002-2922-6607 priscillamartinssilva@gmail.com

Resumo: Este artigo tem como objetivo compreender o processo de formação das Representações Sociais (RS) de competência dos profissionais que atuam na unidade central de administração de uma Instituição Federal de Ensino (IFE). A organização encontra-se em processo de mudança e transformação de suas práticas de gestão. Trata-se de uma pesquisa qualitativa em que foram realizados grupos focais com profissionais técnicos administrativos e gestores. A análise dos dados contou com o auxílio do software Alceste. A construção das RS de competência no contexto analisado está relacionada ao processo de avaliação, ao desenvolvimento profissional, ao incentivo institucional à carreira e também à noção de competência como conhecimento, habilidade, atitude e inteligência prática. Essas RS são ancoradas na concepção da burocracia, no formalismo, no jeitinho, na experiência em diferentes organizações e no cotidiano do trabalho. As conclusões propõem uma reflexão sobre como são assimilados e construídos os novos conhecimentos em um processo de mudança em uma organização pública.

Palavras-chave: Competência, Representações Sociais, Ancoragem, Administração Pública, Gerencialismo.

\begin{abstract}
This article aims to understand the process of formation of social representations (SR) of competence for professionals working in the central unit of administration management of a Federal Teaching Institution (FTI). The organization is in the restructuring process that implicates the managerialism practice. Qualitative data were obtained from focus groups comprised of administrative technical professionals and managers within the context of a public organization. Data analysis were assisted by Alceste software. The results reveal the SR components, which are elements related to the evaluation process, professional development and institutional incentive to career, and the notion of competence as knowledge, skills and attitude and competence as practical intelligence. The SR is anchored on the conception of bureaucracy, formalism, "jeitinho", experience in different organizations and on daily work. The conclusions propose a reflection on managerialism.
\end{abstract}

Keywords: Competence, Social Representations, Anchoring, Public Administration, Managerialism.
Resumen: Este artículo tiene como objetivo comprender el proceso de formación de las Representaciones Sociales (RS) de competencia de los profesionales que actúan en la unidad central de administración de una Institución Federal de Enseñanza (IFE). La organización se encuentra en proceso de cambio y transformación de sus prácticas de gestión. Se trata de una investigación cualitativa en la que se realizaron grupos focales con profesionales técnicos administrativos y gestores. El análisis de los datos contó con la ayuda del software Alceste. La construcción de las RS de competencia en el contexto analizado está relacionada al proceso de evaluación, al desarrollo profesional, al incentivo institucional a la carrera y la noción de competencia como conocimiento, habilidad $y$ actitudes e inteligencia práctica. Estas RS están ancladas en la concepción de la burocracia, en el formalismo, en el estilo, en la experiencia en diferentes organizaciones y en el cotidiano del trabajo. Las conclusiones proponen una reflexión sobre cómo se asimilan y construyen los nuevos conocimientos en un proceso de cambio en una organización pública.

Palabras clave: Competencia,
Representaciones Sociales, Anclaje,
Administración Pública, Gerencialismo.

\section{Introdução}

Em meio às transformações ocorridas no mundo do trabalho a partir da reestruturação produtiva surgiu o conceito de competência. Com seus estudos seminais a partir de 1980, o conceito decorre, principalmente, de duas correntes: norte-americana e francesa (Civelli, 1997; Godoy, Antonello, Bido \& Silva, 2009). Recentemente, autores de outros países deram continuidade aos estudos sobre o tema, o que contribuiu para o surgimento de novas vertentes e concepções ligadas à temática (Godoy et al., 2009).

As diferentes correntes que originaram a temática, que possuem ora divergências, ora convergências conceituais em suas discussões, têm permeado variados campos disciplinares como a Administração, a Psicologia, a Sociologia e a Educação, o que, neste caso, pode favorecer a polissemia conceitual e ideológica (Borgo, Bianco \& Colbari, 2013). Ao considerar as relações de trabalho estabelecidas, destaca-se a importância de estudos que envolvem a competência para os variados campos dos saberes e para os Estudos Organizacionais (EO). Ademais, torna-se relevante discutir as mudanças que envolvem o mundo do trabalho e as práticas de gestão articuladas às subjetividades vivenciadas no cotidiano das organizações. Assim, ao considerar a competência inserida nas novas práticas de gestão, podem ser suscitadas

Correspondência/Correspondence: Pablo Augusto Panêtto de Morais. Instituto Federal de Brasília (IFB). Campus Estrutural. Área Especial, 01, Quadra 16, Cidade do Automóvel. Setor Central (Vila Estrutural). 71255200 - Brasília, DF - Brasil pablopanetto@gmail.com 
reflexões que busquem compreender não a prática de gestão em si, mas como as subjetividades influenciam a dinâmica e o contexto social (Borgo, Bianco \& Colbari, 2013).

Dos quatro paradigmas clássicos propostos por Burrell e Morgan (2005), o foco deste estudo volta-se para o paradigma interpretativista. Esse paradigma é considerado pouco explorado nos estudos organizacionais (Reed, 2014). O paradigma interpretativista pode ser articulado a partir de outras teorias, sendo uma delas a Teoria das Representações Sociais (TRS). A pesquisa realizada por Martins-Silva, Silva Junior, Peroni, Medeiros \& Vitória (2016) apresenta um conjunto de estudos que envolvem o uso da TRS no campo dos EO. Esses estudos evidenciam que, embora o uso da TRS nos EO seja incipiente quando comparado com outras áreas do conhecimento, esse corpo teórico demonstra ser pertinente para interpretação e entendimento dos fenômenos organizacionais.

A TRS se aproxima do paradigma interpretativista, pois busca compreender a construção da realidade de um grupo por meio do pensamento social. $\mathrm{Na}$ TRS, a formação do pensamento social pode ser compreendida por meio da objetivação e da ancoragem. A objetivação tem por finalidade tornar físico um elemento abstrato vinculado a concepções iniciais contidas na memória. Já a ancoragem, que é o foco do presente trabalho, ao envolver elementos afetivos, simbólicos, históricos e culturais, realiza o enraizamento e organiza o significado de uma representação social (Moscovici, 2015).

As RS emergem, portanto, nos grupos em dado contexto social, que no caso desta pesquisa é o contexto público, o qual é permeado por valores, elementos simbólicos, processos, rotinas e mudanças. Dentre as mudanças, destacam-se as formas gestionárias, como a gestão por competência, que no âmbito da pesquisa aproxima-se do modelo gerencialista. O modelo gerencialista, conforme propõem Caldas e Alcadipani (2012), é caracterizado pela migração para o contexto público de práticas utilizadas por empresas privadas. Os cidadãos são vistos como clientes e os discursos enfatizam a eficiência da administração.

Na perspectiva de compreender a formação do pensamento social (em que estão envolvidos o senso comum e os diversos saberes) sobre competência dos profissionais técnicos administrativos e gestores de uma IFE, o presente trabalho procura responder a seguinte problemática de pesquisa: como ocorre o processo de formação das representações sociais de competências dos profissionais que atuam na unidade central de administração de uma Instituição Federal de Ensino?

A relevância do estudo sobre competência a partir da Teoria das Representações Sociais na IFE que constitui o locus desta pesquisa ancora-se em como diferentes aspectos que envolvem 0 senso comum, que está alinhado a sentimentos, valores, normas e pensamentos dos sujeitos em seus grupos de pertença, podem auxiliar na compreensão das relações subjetivas que são construídas na organização. A lente interpretativista, da qual este estudo se aproxima, é considerada pouco explorada nos estudos organizacionais (Reed, 2014), demonstrando, portanto, a pertinência deste estudo.
A abordagem societal, que compreende o processo de constituição das RS e auxilia na articulação e no processo de compreender a formação do pensamento social em vários níveis de análise, é utilizada, portanto, de forma limitada no Brasil (Almeida, 2009; Trindade, Santos \& Almeida, 2014; Martins-Silva et al., 2016). Ressalta-se que, embora haja diferentes abordagens no campo da TRS, elas não são demarcações incompatíveis entre si, pelo contrário, as abordagens são consideradas complementares (Trindade; Santos; Almeida, 2014).

Mais especificamente, a presente pesquisa é relevante por lançar luz na formação de RS de competências no contexto público, o qual tem passado por mudanças no sentido de incorporar práticas gerenciais de organizações privadas (Caldas \& Alcadipani, 2012). A compreensão da formação de RS de competências para servidores públicos apresenta-se como um indicativo de como o setor público tem lidado com os diferentes aspectos relacionados a esse processo de mudança que envolve a cultura, os afetos, os sentimentos e os valores dos envolvidos, e consequentemente, a prática cotidiana no trabalho.

Este artigo está estruturado em cinco sessões além desta introdução. Na segunda seção são apresentadas as demarcações que contemplam o referencial teórico. Em seguida, na terceira seção, são delineados os aspectos metodológicos. Na quarta seção destaca-se a apresentação dos resultados e discussão. Por fim, na quinta seção, algumas considerações são tecidas.

\section{Referencial Teórico}

\section{A formação das Representações Sociais: objetivação e ancoragem}

A TRS dispõe de um arcabouço conceitual que tem sido utilizado por diversas áreas do conhecimento (Eicher, Emery, Maridor, M. Gilles, \& Bangerter 2011), dentre elas observa-se o seu uso nos EO (Martins-Silva et al., 2016). Em um estudo bibliométrico que investigou os artigos em EO publicados entre anos de 2001 a 2014, Martins-Silva et al. (2016) identificaram que a TRS tem sido utilizada com mais frequência relacionada aos seguintes objetos sociais: 1) profissões, carreira e trabalho; 2) gestão; 3) gênero; e, 4) Recursos Humanos ou Gestão de Pessoas. No estudo os autores verificaram que dentre as diferentes abordagens em TRS, a societal corresponde a uma das abordagens menos utilizadas. Ainda neste estudo foi possível observar que os processos de formação das RS foram pouco utilizados nos artigos investigados (Martins-Silva et al., 2016).

Dentre os diversos conceitos teóricos presentes na TRS, destacam-se dois conceitos basilares denominados objetivação e ancoragem, que são os processos formadores das RS. Esses mecanismos são considerados processos maiores, complementares e geradores das RS, em que o social transforma o conhecimento em representação e essa, por sua vez, transforma o social (Moscovici, 2015).

A ancoragem, por meio da classificação e categorização, traz determinado fenômeno ou conceito para um plano considerado familiar na representação social. Possibilita, portanto, o enraizamento da RS, estabelecendo as categorias socialmente e 
realizando a integração cognitiva de um objeto representado a um sistema familiar ou preexistente. Sendo assim, a ancoragem tem a função de dar um sentido inteligível dentro de um contexto (Moscovici, 2015). O processo de objetivação possibilita a materialização de um conceito abstrato, ou seja, torna concreta a realidade, transformando o elemento inicialmente abstrato, complexo ou novo, em um elemento concreto, um conceito ou imagem concreta e significativa, apoiando-se em concepções que são familiares (Moscovici, 2015).

Moscovici (2015), em seu primeiro trabalho sobre a TRS, exemplifica esses dois processos na psicanálise, na qual a terapia é uma estranha medicina sem remédios, mas, ao mesmo tempo, assemelha-se a uma confissão religiosa. Um outro exemplo é o estudo sobre infertilidade feminina de Trindade e Enumo (2001), que identificou que a infertilidade para as mulheres entrevistadas está ancorada na associação simbólica mulher-natureza e a sua objetivação encontra forma nas seguintes imagens: tronco oco, árvore seca e terra árida.

$\mathrm{Na}$ concepção das representações sociais é evidenciada a importância do papel praticado pelos atores sociais em sua produção e transformação. Neste sentido, os indivíduos elaboram as representações do campo social no qual estão inseridos e, dessa forma, posicionam-se, constroem redes relacionais e delineiam elementos simbólicos, comportamentos, opiniões, valores e crenças em um contexto de reconstrução continuada das RS (Cabecinhas, 2004).

Em um estudo envolvendo a ancoragem e a objetivação com grupos considerados marginalizados, Arruda (2014) traz contribuições importantes em relação aos processos de formação das RS. Sua pesquisa, realizada na região periférica do Estado do Rio de Janeiro, abordando o universo do funk, revela que esse movimento era considerado clandestino, em virtude de, à época, sua veiculação ser proibida na mídia oficial, sendo, contudo, muito presente em bailes de comunidades cariocas (Arruda, 2014). De acordo com a autora, a juventude favelada, pobre e periférica, que frequentemente é associada à figura de vagabundos e infratores, com a disseminação do funk, passou a vestir-se com outra roupagem: os "funkeiros". Dessa forma, por intermédio do papel representado pelo funkeiro, o funk, um estilo musical de gueto e uma arma de luta simbólica, passou a ancorar-se em uma representação hegemônica da sociedade, que estigmatizava a cor da pele, a pobreza e a marginalidade (Arruda, 2014). Destaca-se, no entanto, de acordo com a autora, que muitos dos entrevistados declaravam-se não simpatizantes ao estilo musical. Contudo, a experiência em campo realizada por seu grupo de pesquisa permitiu encontrar essas mesmas pessoas nos bailes funk das comunidades (Arruda, 2014).

Assim, para a autora, o estudo do processo de formação das RS é mais abrangente do que o mero conteúdo semântico de uma representação, compreendendo conteúdos que delineiam as relações simbólicas entre os atores sociais. Dessa forma, a ancoragem supera os elementos cognitivos e semióticos, propicia uma nova lente para a compreensão do mundo e remodela os comportamentos, valores e sentidos de uma sociedade (Arruda,
2014). No presente estudo, o foco é o processo de ancoragem das RS de competência.

\section{A Abordagem Societal das Representações Sociais}

A RS é originada a partir do contexto social, ou seja, por meio da compreensão de um grupo para com o outro, onde a posição social de um membro de um grupo afetará diretamente sua compreensão da realidade. Sendo assim, a TRS tem como foco o sujeito, que, em sua vinculação com o universo, é tanto construtor do mundo, como de si mesmo, fruto das dinâmicas sociais existentes, em que indivíduo e grupo se afetam e são afetados mutuamente (Doise, 1982; Mendonça \& Lima, 2014).

Dentre as três abordagens observadas na TRS optou-se por utilizar a abordagem societal proposta por Willem Doise, que busca associar o individual ao coletivo, procurando nas esferas individual e coletiva, explicações a respeito de como as dinâmicas sociais influenciam o indivíduo na coletividade, sendo essas dinâmicas interacionais, posicionais ou de valores e de crenças gerais (Mendonça \& Lima, 2014; Trindade, Santos \& Almeida, 2014). Nesse sentido, a abordagem societal, ao possibilitar a compreensão do pensamento social do grupo, presume a articulação de quatro processos de análises na construção e manifestação do pensamento social: processos intraindividuais, processos interindividuais, processos intergrupais e, por fim, societal ou ideológico (Doise, 2010; Trindade, Santos \& Almeida, 2014).

A esfera de processos intraindividuais parte da análise de como os indivíduos articulam suas experiências com o mundo externo. $\mathrm{Na}$ esfera interindividual investigam-se por meio dos sistemas interacionistas as elucidações das dinâmicas sociais. Na terceira esfera, intergrupal, analisam-se as modificações de posicionamento social face aos diferentes grupos dos quais os indivíduos fazem parte. Sendo assim, para essa esfera, as diferentes posições dos atores nas relações sociais devem ser levadas em consideração. Por fim, na quarta esfera, a societal ou ideológica, estão presentes as crenças, representações e normatizações sociais que orientam e dão sentido aos comportamentos dos indivíduos a partir de normas mais abrangentes, remetendo assim a questões culturais e ideológicas (Doise, 2010).

Um exemplo de estudo no campo dos EO que utilizou a abordagem societal foi a pesquisa realizada por Souza, Serafim, \& Dias (2010). Essa pesquisa teve como objetivo compreender o fenômeno da RS das organizações não-governamentais entre aqueles que conduzem as organizações sociais. Os resultados encontrados evidenciam os quatro níveis de análise propostos por Doise (2014) e identificam que a formação profissional e aspectos relacionados à inserção social do gestor são determinantes para a organização das RS.

Cabe destacar que a abordagem societal aponta para questões sociológicas, considerando a presença do indivíduo nos grupos, sendo este um fator preponderante na variação das $R S$, através da ligação entre a individualidade e a coletividade. Assim, a formação das RS não ocorre somente através dos mecanismos cognitivos individuais, mas também leva em consideração as características dos grupos (Doise, 2010). No presente estudo adotou-se os níveis 
de análise intergrupal e societal, pois presume-se que a filiação dos indivíduos em grupos de pertenças (nesta pesquisa apresentados em duas categorias: gestores e técnicos administrativos) afeta diretamente o processo de constituição de uma RS.

\section{Competência}

Competência, que é o objeto social da presente pesquisa, é uma terminologia que surgiu no contexto das modificações ocorridas no mundo do trabalho a partir da reestruturação produtiva. No campo da Administração, competência compreende acepções acerca do trabalho empreendido pelos atores nas diversas organizações e envolve tanto a discussão acerca do indivíduo, como também, da organização (Martins-Silva, Silva, Souza \& Silva Júnior, 2014). As principais correntes teóricas sobre o tema são a norte-americana e a francesa.

A discussão sobre competência teve início nos Estados Unidos em 1973, por David Clarence McClelland, com a publicação do artigo intitulado Testing for competence rather than intelligence na revista American Psychologist (Martins-Silva et al., 2014). David McClelland propõe as competências diferenciadoras dos indivíduos, isto é, competências que diferenciam um indivíduo do outro e que permitem uma performance superior (Martins-Silva et al., 2014).

A abordagem norte-americana sobre competências tem similaridade com as versões contemporâneas do modelo taylorista/fordista e percebe a competência como algo relacionado ao cargo, sendo produzida por meio da integração do conhecimento, das habilidades e da atitude do indivíduo, definição também conhecida como CHA (Fleury \& Fleury, 2001). Essas características são passíveis de generalizações em diversas situações de trabalho e persistem por um período de tempo razoável (Boyatzis, 1982). Nessa corrente, competência é entendida como a quantidade de qualificações que proporcionam a atuação do trabalhador em patamares considerados elevados, sendo estas qualificações previamente definidas e dimensionadas (McClelland, 1973; Boyatzis, 1982; Borgo, Bianco \& Colbari, 2013). Sendo assim, a sua avaliação é realizada por meio das qualificações adquiridas e do desempenho no cargo.

$\mathrm{Na}$ escola francesa a competência compreende a capacidade de iniciativa do trabalhador, em um dado contexto de trabalho em que este supera as atividades prescritas, bem como eventualidades nas situações de trabalho, sendo estas a base para que 0 trabalhador seja considerado competente. Nesse sentido, a competência está para além do estoque de conhecimentos teóricos e empíricos do trabalhador, e não se limita à mera execução da tarefa (Zarifian, 2011). Na concepção francesa, o indivíduo incorpora um papel de ator, em que sua ação no trabalho ultrapassa a prescrição da atividade, e seu comportamento passa a ser considerado como um saber agir diante de determinada circunstância, também podendo ser denominada de inteligência prática. A atuação do trabalhador rompe as barreiras da prescrição e dá destaque a iniciativa e a capacidade de atuação dentro de um evento, seja esse evento programado ou não. Dessa forma, a competência é considerada um elemento em permanente construção pelo indivíduo que está em interação com os grupos profissionais e sociais que compõem o ambiente no qual está inserido (Le Boterf, 2003). Diante dessa realidade, a avaliação da competência deve ser realizada com base na forma de fazer o trabalho e no resultado alcançado (Le Boterf, 2003).

No Brasil, o tema vem sendo desenvolvido com as ideias presentes nas vertentes consideradas precursoras e gerando outros desdobramentos nas discussões. Constata-se, assim, que competência se dissemina em diversos tipos de abordagens, discussões e em variados campos dos saberes, e que não se estabeleceu um consenso nos estudos que envolvem o tema (Ruas, 2005; Zago \& Retour, 2013).

O conceito de competência é considerado em construção e sua discussão tem se disseminado pelas organizações, que buscam inseri-lo no cotidiano organizacional, pelas diversas necessidades apresentadas pelo mundo do trabalho. Com o objetivo de compreender como a competência é entendida nas organizações, Martins-Silva et al. (2014) investigaram as RS de competências entre administradores vinculados no Conselho Regional de Administração - Seccional ES. Os resultados demonstram que os elementos essenciais da RS são: conhecimento, habilidade, atitude, responsabilidade e comprometimento. Segundo os autores, embora a noção de competência, em termos teóricos, articule um conjunto de conceitos, partes diferentes das correntes teóricas (norteamericana e francesa) são coordenadas para construir um sentido sobre o que é competência.

\section{Gerencialismo}

Uma das práticas gerenciais adotadas pelo governo brasileiro refere-se à tentativa de implementação da gestão por competências, estritamente gerencialista. Essa aplicação tem por finalidade a articulação das competências dos trabalhadores para a eficácia organizacional das instituições públicas, a exemplo da Lei n. ${ }^{11}$ 11.091/2005 e do Decreto n. ${ }^{1} 5.707 / 2006^{2}$. Esse é apenas um dos exemplos observados, que indicam a presença de um processo de mudança em relação ao modelo de administração pública brasileira (Mello et al., 2013).

O gerencialismo defende a descentralização política e administrativa, a redução dos níveis hierárquicos, a orientação para a produtividade, a eficiência, a competição e a definição de objetivos e resultados. É visto como um movimento composto, de um lado, por uma coletividade de ferramentas de gestão e, de outro, por uma filosofia utilizada pela administração pública, sendo disseminado pelos países mundo afora. Aspectos culturais, políticos e econômicos, tanto em uma dimensão global quanto local, influenciam sua implementação, visando a transformação de estruturas burocráticas em estruturas gerenciais, na busca pela eficiência e produtividade organizacional (Secchi, 2009).

A transposição de práticas gerenciais consideradas "universais" a quaisquer tipos de organização é questionada por Caldas e Alcadipani (2012). Esses autores destacam que o "americanismo" ou "americanização" idealizam uma gestão aplicável a todo tipo de organização, independentemente do local e contexto onde esteja inserida, desconsiderando, assim, fatores como a dinâmica 
histórica e sociocultural e demais elementos simbólicos que permeiam uma organização. A importação de práticas gerenciais comumente é vista no campo da gestão e nos EO, porém tem se estendido também aos sistemas de ensino adotados no país (Caldas \& Alcadipani, 2012), foco do presente artigo.

Riggs (2010) defende que a simples importação da racionalidade administrativa aplicada em outras localidades poderá ser fracassada, uma vez que diversos fatores subjetivos estão envolvidos. Dessa forma, o autor propõe o conceito de formalismo no qual o comportamento do indivíduo não se enquadra em uma prescrição normativa, além disso, o que é identificado nas normas prescritas não corresponde ao que de fato os indivíduos desenvolvem na realidade. Sendo assim, os instrumentos normativos estabelecem diretrizes que não são realizadas na prática e não correspondem à realidade social, sendo incapazes, inclusive, de modificá-la (Riggs, 2010).

Ao encontro das concepções de Riggs (2010) acerca do formalismo, Bernardo, Shimada e Ichikawa (2015) apresentam que ele se caracteriza pela desarmonia entre o comportamento, as ações das pessoas e a ordem social, entre o legalmente preestabelecido e o acontecimento na prática social. Em outras palavras, corresponde à divergência entre o comportamento prescrito e o comportamento representado e também entre a norma e a prática (Bernardo, Shimada \& Ichikawa, 2015).

No Brasil, as pessoas buscam contornar os obstáculos decorrentes do formalismo por meio de uma prática conhecida como "jeitinho". Nesse sentido, o "jeitinho" é a alternativa que justifica a falta de aderência às normativas, às leis, às instituições e às crenças de hábitos estabelecidos, sendo que a imposição de tais elementos favorece demasiadamente a prática do "jeitinho" (Bernardo, Shimada \& Ichikawa, 2015).

O "jeitinho" encontra-se entre o legal e o ilegal, o moral e o imoral, portanto, um comportamento alternativo que, situado entre a polaridade do correto e do incorreto, encontra aprovação pelo grupo (Bernardo, Shimada \& Ichikawa, 2015). Sendo assim, o "jeitinho" se caracteriza como uma prática social que tem como raiz o formalismo e é utilizado como uma alternativa de solução de entraves ou para facilitar determinada situação, margeando, assim, questões consideradas burocráticas.

O formalismo consiste de uma arbitrariedade, enquanto o "jeitinho" expressa-se de uma alternativa mais rápida e criativa de alcançar uma finalidade desejada. Ademais, a expressão "jeitinho" reflete uma prática demasiadamente comum no serviço público brasileiro, se relacionada aos mecanismos utilizados pelas pessoas para contornarem o formalismo presente no cotidiano burocrático das organizações públicas (Bernardo, Shimada \& Ichikawa, 2015).

O modelo de gestão burocrático é conhecido como uma estrutura social que possibilita previsibilidade e precisão à administração, por meio do aspecto técnico e racional da gestão. Nesse modelo, os deveres dos membros da organização são formalizados e a autoridade é manifestada de forma hierárquica predominantemente vertical e definida em uma concepção impessoal, onde prevalecem a distinção entre o cargo exercido e a pessoa que o exerce. Assim, a formalidade das ações ganha destaque com as responsabilidades e deveres atribuídos a cada membro da organização, legitimando, desta forma, a hierarquia, o regulamento, os procedimentos, os documentos, as decisões e a comunicação (Secchi, 2009).

No contexto de redução de custos, diminuição de gastos, foco na produtividade e nos resultados, bem como nas responsabilidades de cada integrante da organização, o modelo gerencialista também busca a eficiência da administração pública. Entretanto, esse modelo advém da necessidade de uma administração mais flexível, com estruturas horizontalizadas, buscando a atenuação dos custos e o aumento da qualidade dos serviços prestados pela organização. É caracterizado, portanto, por decisões e ações voltadas para metas, com foco nas demandas dos usuários e no controle dos resultados. Ele almeja, desta forma, a eficiência, a eficácia e a competitividade (Secchi, 2009).

O modelo gerencialista tem como inspiração os modelos de gestão adotados na iniciativa privada, como, por exemplo, a avaliação de desempenho. Dessa forma, colocando à margem o apego a normas e tarefas a serem executadas, a administração pública busca o alcance de objetivos e resultados por meio de indicadores de desempenho que devem guiar a organização e seus membros (Secchi, 2009).

No âmbito do serviço público, a avaliação de desempenho é um objeto relativamente intrincado e que, além de afetar a valorização profissional por meio de aspectos remuneratórios, volta-se também para a profissionalização da administração pública. Assim, a avaliação de desempenho perpassa aspectos que abrangem tanto a eficiência organizacional na busca por resultados, como também a remuneração do profissional, que advoga pelo desenvolvimento e motivação do servidor. Nessa perspectiva, algumas críticas são tecidas, pois a despretensiosa transposição de técnicas gerenciais da iniciativa privada para a pública pode resultar em adversidades gerenciais, dados aspectos singulares das organizações públicas (Cavalcante \& Carvalho, 2017).

Santana, Reis, Reis e Tavares (2013), por meio de um estudo em que foi articulada a Teoria das Representações Sociais a Administração Pública, destacam que recortes teóricos e metodologias de cunho subjetivo e qualitativo são relevantes para a descoberta de informações e realidades que fazem uso de técnicas instrumentais de gestão aplicadas. Nesse sentido, a compreensão da construção das RS de competência no setor público pode contribuir para o entendimento de como o sistema burocrático lida com elementos culturais, formalísticos e com a prática gerencialista.

\section{Aspectos Metodológicos}

Esta pesquisa caracteriza-se como uma pesquisa qualitativa. Uma das finalidades da pesquisa qualitativa é abordar as diferentes representações sobre determinado assunto, tais quais são voltadas para a compreensão de aspectos ligados ao mundo social onde os indivíduos de um determinado grupo estão inseridos (Gaskel, 2013).

A pesquisa teve como locus de estudo uma Instituição Federal de Ensino localizada na região sudeste do Brasil, aqui identificada 
com o nome fictício de "Ômega". A instituição possui aproximadamente dois mil e quinhentos profissionais em seu quadro de pessoal e conta com aproximadamente dezenove mil alunos matriculados. A IFE está inserida no contexto do Decreto $\mathrm{n}^{\circ}$ 5.707/2006, que instituiu a política de desenvolvimento de servidores do Executivo Federal. Por meio dele, entrou em discussão no serviço público a gestão por competências. Nessa perspectiva, podem ser observados na IFE elementos tanto políticos quanto práticos e processuais.

Os elementos políticos podem ser observados, na concepção do decreto, enquanto princípios e diretrizes a serem seguidos pelos órgãos do executivo federal, que é o caso da IFE. Entretanto, não é possível afirmar uma política própria estabelecida na instituição pesquisada. Nesse sentido, os elementos práticos e processuais transitam próximos e podem ser mais perceptíveis na instituição, ao serem adotadas ações gerenciais que buscam atender ao estabelecido na legislação, que aborda o desenvolvimento de competências dos servidores. Em outras palavras, as práticas adotadas na instituição, como, por exemplo, a ferramenta de avaliação dos profissionais, bem como normativas internas que abordam o desenvolvimento destes, encontram-se no bojo instrumental da gestão por competências, sendo norteadas pelo decreto. Assim, ao serem estabelecidas na IFE algumas práticas ferramentais da Administração habitualmente utilizadas em empresas privadas, notam-se ações gerencialistas em processo de implementação na instituição. Sendo assim, no contexto da IFE pesquisada, podem ser percebidos elementos políticos, práticos e processuais da gestão por competências.

Para esta pesquisa optou-se como unidade de observação a estrutura de gestão de uma das pró-reitorias da instituição, denominada neste trabalho de Pró-Reitoria "Delta". Esta PróReitoria é a instância institucional máxima, responsável por ações referentes à gestão de pessoas, executadas por uma diretoria relacionada a essa área, tendo, portanto, vinculação mais estreita com a política estabelecida no Decreto $n^{\circ}$ 5.707/2006, demais instrumentos normativos e elementos que envolvem a gestão por competências em sua perspectiva política, prática e processual.

Além disso, essa pró-reitoria é composta por um dimensionamento maior de membros em relação às demais, sendo composta por 60 profissionais, incluindo os três gestores de cada uma das diretorias a ela vinculadas, bem como os respectivos profissionais técnicos administrativos lotados nessas três diretorias, neste trabalho denominadas Diretoria Alfa, Diretoria Beta e Diretoria Gama. Ressalta-se que, no contexto de uma IFE, essas atividades são consideradas como atividades-meio, já que a categoria docente dessas instituições desenvolvem as atividades-fim.

Como procedimento de coleta de dados, optou-se pela realização de grupos focais, moderados por uma psicóloga, no entendimento de que a formação em Psicologia dá maior aptidão para mediar possíveis conflitos pessoais e grupais que pudessem ocorrer durante as sessões e, também, com conhecimento prévio sobre o tema competência, tratado nesta pesquisa. Foram realizados quatro grupos focais, totalizando seis horas e quarenta e cinco minutos de duração com vinte e um sujeitos. Cada sessão de grupo focal se limitou ao máximo de oito participantes, conforme proposto por Gaskel (2013). A caracterização dos grupos é apresentada a seguir por meio do Quadro 1. Destaca-se que foi utilizado nomes fictícios para preservar a identidade dos participantes.

Quadro 1 - Caracterização dos participantes

\begin{tabular}{|c|c|}
\hline Grupo & Dados \\
\hline $\begin{array}{l}\text { Grupo dos Gestores } \\
\text { Participantes: Damares, Eli, Josafá }\end{array}$ & $\begin{array}{l}\text { Média de idade: } 38 \text { anos (DP: } 12,1) \\
\text { Média de tempo na instituição: } 8,6 \text { anos (DP: 1,5) } \\
\text { Formação: Educação Física, Engenharia de Produção, Análise de Sistema }\end{array}$ \\
\hline $\begin{array}{l}\text { Grupo Alfa } \\
\text { Participantes: Felipe, Gideão, Mara, } \\
\text { Raquel, Salomé, Talita }\end{array}$ & $\begin{array}{l}\text { Média de idade: } 35 \text { anos (DP: } 7,2 \text { ) } \\
\text { Média de tempo na instituição: } 3,6 \text { anos (DP: 1,2) } \\
\text { Formação: Engenharia Ambiental, Ciências Econômicas, Enfermagem, Sistema de } \\
\text { Informação, Engenharia de Produção }\end{array}$ \\
\hline $\begin{array}{l}\text { Grupo Beta } \\
\text { Participantes: Golias, Hermes, Lia, } \\
\text { Rubem, Rebeca }\end{array}$ & $\begin{array}{l}\text { Média de idade: } 40 \text { anos (DP: } 12 \text { ) } \\
\text { Média de tempo na instituição: 2,8 anos (DP: d,3) } \\
\text { Formação: Ensino Médio, Engenharia Civil, Arquitetura e Urbanismo, Engenharia elétrica, } \\
\text { Técnico em Eletrotécnica }\end{array}$ \\
\hline $\begin{array}{l}\text { Grupo Gama Participantes: Ananias, } \\
\text { Levi, Lídia, Rufo, Rita, Sara }\end{array}$ & $\begin{array}{l}\text { Média de idade: } 35,6 \text { anos (DP: } 4,0 \text { ) } \\
\text { Média de tempo na instituição: } 5,6 \text { anos (DP: } 2,8) \\
\text { Formação: Análise e Desenvolvimento de Sistemas, Ensino Médio, Análise e } \\
\text { Desenvolvimento de Sistemas, Sistema de informação, Pedagogia, Pedagogia }\end{array}$ \\
\hline
\end{tabular}

Os grupos focais foram transcritos e depois analisados com o auxílio do software Alceste (Análise Lexical de Coocorrências em Enunciados Simples de um Texto). Desenvolvido por Max Reinert, esse programa realiza diversos procedimentos de análise nos bancos de dados textuais. Nesse sentido, o Alceste possibilita a avaliação de objetos com base nas opiniões dos participantes. Assim, tem como propósito fragmentar um texto para extrair as estruturas mais significativas, descrevendo e classificando os principais elementos de um conjunto discursivo (Camargo, 2005; Kronberger \& Wagner, 2013).
Proveniente da transcrição integral, o conjunto discursivo dos grupos focais perfez 53.491 palavras, sendo tratado semanticamente, conforme recomendações do software. O software realizou duas classificações sucessivas, em que $72 \%$ das unidades de contexto elementar (UCE) do corpus foram classificadas, superando os 50\% indicados por Camargo (2005), como também os $70 \%$ de classificação aceitáveis, defendido por Kronberger e Wagner (2013). Foram retornadas 400 UCE, superando as 250 respostas curtas recomendadas por Camargo 
(2005). Diante desses dados, o resultado pode ser considerado viável.

As classes de palavras demonstradas através do dendrograma indicam mundos lexicais presentes no conjunto discursivo. Os mundos lexicais representam vocabulários e combinações de palavras utilizadas pelos sujeitos que indicam elementos cognitivos partilhados, que são integrantes de RS (Lima, 2008). Para a identificação dos diferentes tópicos do mundo lexical presente em cada classe de palavras utilizou-se a técnica de análise de conteúdo (Franco, 2003). Dessa forma, as categorias identificadas em cada classe de palavras foram definidas a posteriori, após análise do relatório disponibilizado pelo software Alceste composto de dicionários, ocorrências de palavras, ilustrações, dentre outros, que integrou o corpus da pesquisa. Com o relatório foram realizadas leituras flutuantes e as categorias foram criadas observando a exaustividade e a representatividade léxica que, de acordo com Franco (2003, p. 51), corresponde à "classificação de palavras segundo seu sentido, emparelhamento dos sinônimos e sentidos próximos".
Ressalta-se que a pesquisa seguiu as diretrizes estabelecidas na Resolução n 466, de 12 de dezembro de 2012, do Conselho Nacional de Saúde (Conselho Nacional de Saúde, 2012) e aprovada pelo Comitê de Ética em Pesquisa. Além disso, todos os entrevistados foram informados previamente sobre a finalidade da pesquisa e solicitada autorização de participação por meio de Termo de Consentimento Livre e Esclarecido.

\section{Resultado e Discussão}

Ao considerar os tópicos discursivos, as classes foram denominadas, conforme análise e interpretação dos aspectos presentes nas classes, da seguinte forma: a Classe 3 corresponde à Competência no Cotidiano; a Classe 4 corresponde à Competência e Pessoas; a Classe 2 corresponde ao Contexto e a Classe 1, à Avaliação. As classes compreenderam uma árvore de palavras demonstrada graficamente por meio do seguinte dendrograma:

Figura 1 - Dendrograma do Corpus

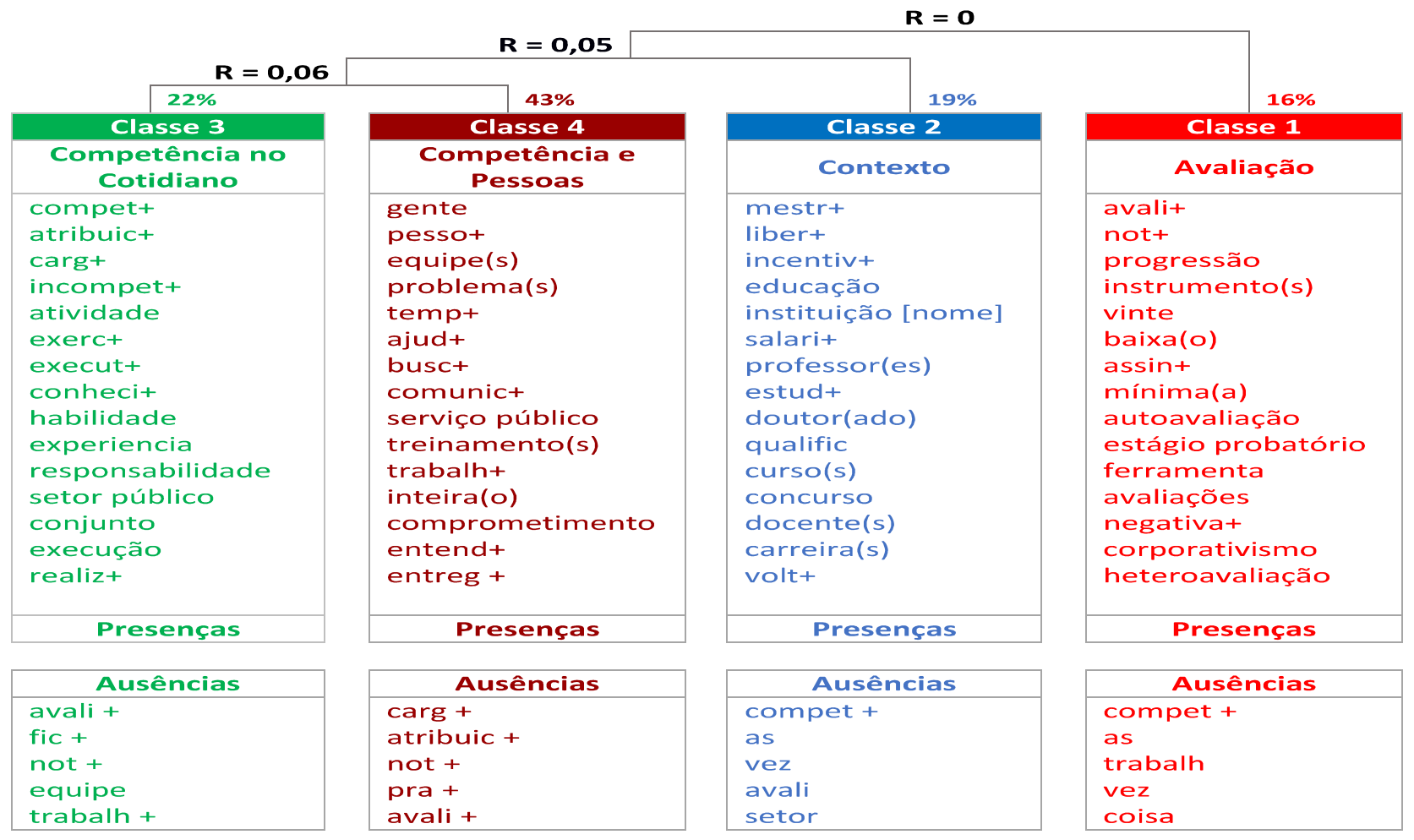

O dendrograma evidenciou por meio de raízes semânticas possibilidades interpretativas em cada classe. Procurou-se, então, compreender o processo de formação das RS de competência a partir das classificações empreendidas pelo Alceste. Para tanto, a discussão segue dimensionada em três tópicos, sendo eles: 1) Avaliação, 2) Contexto, e 3) Competência como CHA e Inteligência Prática.

\section{Avaliação}

A Classe "Avaliação" tratou da dimensão avaliativa na prática organizacional. Essa classe foi a mais específica e a primeira a ser distinguida na árvore de classificação pelo software, e representa $16 \%$ na classificação. A seguir estão as falas dos participantes que, segundo a análise do Alceste, representam elementos cognitivos partilhados (Lima 2008). 
Quadro 2 - UCE da Classe "Avaliação"

\begin{tabular}{|c|c|}
\hline Trechos de UCE & Tópicos do mundo lexical \\
\hline $\begin{array}{l}\text { "Isso precisa (ser) (aprimorado), mas tem (feedback) [a avaliação]. Tem (sido) muito proveitoso. (Ele) [instrumento de } \\
\text { avaliação] (avalia) (quatro) (eixos): (ele) (avalia) a questão operacional, (avalia) a parte de liderança, a parte (ética), de } \\
\text { (desenvolvimento) também, de relacionamento interpessoal". [sic] Damares, Gestor. }\end{array}$ & \multirow{2}{*}{$\begin{array}{l}\text { Aspectos construtivos da } \\
\quad \text { avaliação }\end{array}$} \\
\hline $\begin{array}{l}\text { "Eu acho que o (formulário) (pode) (melhorar), mas ainda (assim) eu valorizo que tem uma (avaliação de desempenho), } \\
\text { uma regularidade que é cobrada, porque tem um sistema que manda, que cobra da (chefia)" Salomé, Alfa. }\end{array}$ & \\
\hline $\begin{array}{l}\text { "(É) (feita) através de um (questionário) de (autoavaliação) e (heteroavaliação). E a hétero é (feita) com os (colegas), com } \\
\text { os (pares), com a (chefia). (A) sua (chefia) é a diretoria na verdade. No meu entender eu acho que não (funciona) muito } \\
\text { não, porque as perguntas são as mesmas. Entra ano, sai ano, (sempre) a mesma coisa, entendeu?! As mesmas } \\
\text { perguntas" Raquel, Alfa. }\end{array}$ & \multirow{2}{*}{$\begin{array}{l}\text { Aspectos desfavoráveis da } \\
\text { avaliação }\end{array}$} \\
\hline $\begin{array}{l}\text { "(Ele) é essa (nota). Não (ele) não é (cem por cento), e nisso o (instrumento) precisa (melhorar). (Ele) não é (quase) } \\
\text { sempre que é o (quinze), mas (ele) não é (sempre), vamos colocar que (ele) é (dezoito), que não tem no (instrumento)" } \\
\text { Damares, Gestor. }\end{array}$ & \\
\hline $\begin{array}{l}\text { "Eu (já) vi (avaliação) que a pessoa só (assinou). Eu (já) vi (avaliação) que o (instrumento) de (avaliação), o (formulário), } \\
\text { (já) estava preenchido. Tem que (ter) cinco assinaturas. Aqui você (pode) (assinar) minha (avaliação)?"Talita, Alfa. }\end{array}$ & \multirow[b]{2}{*}{$\begin{array}{l}\text { Aspectos corporativistas e } \\
\text { formalísticos da avaliação }\end{array}$} \\
\hline $\begin{array}{l}\text { "Você não passa por (qualquer) insegurança. Você é desse jeito mesmo. (Simplesmente) (já) passa pelo mal } \\
\text { entendimento do próprio (questionário). (E) depois por um (corporativismo). (Todo) (mundo) (avalia) (bem) porque se } \\
\text { você não (avaliar) (bem), não, na sua eu vou te dar o troco e você não vai receber a sua (progressão)" Josafá, Gestor. }\end{array}$ & \\
\hline
\end{tabular}

Fonte: Alceste. Adaptado pelos autores.

Nota: Entre parênteses estão as palavras que formam a classe de palavras fornecida pelo software Alceste. Entre colchetes estão as palavras incluídas no processo de transcrição.

$\mathrm{Na}$ instituição Ômega são utilizados dois formulários no processo de avaliação dos profissionais técnicos administrativos: o formulário de autoavaliação e o de heteroavaliação. O formulário de autoavaliação tem a finalidade de aferir a dimensão operacional (conhecimento, eficácia e eficiência) e a dimensão comportamental (motivação e trabalho em equipe) dos profissionais. O formulário de heteroavaliação, por sua vez, mensura o aspecto operacional (conhecimento, criatividade e rendimento), o aspecto organizacional (comprometimento, responsabilidade e segurança) e o aspecto comportamental (iniciativa, trabalho em equipe, relacionamento e adaptabilidade). Os quesitos elencados em ambos os formulários são avaliados da seguinte forma: Sempre (20 pontos), Quase sempre (15 pontos), Às vezes (10 pontos) ou Nunca (5 pontos)

A avaliação demonstra uma prática adotada na organização com a finalidade de mensurar o desempenho das atividades realizadas pelos trabalhadores no cotidiano organizacional. Essa prática compreende a avaliação de desempenho, apontada pelos grupos como uma forma de destacar aspectos relacionados à competência do trabalhador. O tipo de avaliação apresentada nas falas relaciona-se com a avaliação utilizada pela corrente norteamericana de competência, na qual existem qualificações previamente definidas e dimensionadas (McClelland, 1973; Boyatzis, 1982; Borgo, Bianco \& Colbari, 2013). No discurso dos participantes, além da descrição da avaliação realizada na organização, também esteve presente elementos relacionados ao formalismo (Riggs, 2010) e ao "jeitinho" (Bernardo, Shimada \& Ichikawa, 2015).

Embora valorizem a existência da avaliação, na prática, os sujeitos utilizam formas alternativas ou "jeitinho" (Bernardo, Shimada \& Ichikawa, 2015) para a sua realização, sendo esse um subterfúgio de manobrar a regra predominante. Através dos dados não é possível afirmar que a avaliação mensure aspectos voltados ao que os grupos consideram como competência. Entretanto, foi possível verificar que mesmo em processo de mudança, considerada pelo grupo dos gestores uma mudança "cultural", a prática da avaliação continua enraizada no formalismo (Riggs, 2010), no "jeitinho" e no corporativismo (Bernardo, Shimada \& Ichikawa, 2015).
$\mathrm{Na}$ instituição Ômega, os aspectos voltados para o "jeitinho" ganham fôlego, já que predominam a burocracia (Kobal, Teixeira Filho, \& Aquino Cabral, 2012), que, por sua vez, pode favorecer a sua prática. A burocracia possui características voltadas para a racionalidade, a impessoalidade, e compreende elementos meramente técnicos, impregnados pelo formalismo, o que pode aumentar o hiato entre a norma e a prática, assim como entre o trabalho prescrito e o trabalho real, conforme proposto por Riggs (2010).

As práticas que envolvem a abordagem da competência têm sido utilizadas de forma meramente instrumental, sem levar em consideração o contexto, o envolvimento das pessoas e compreende, na maioria das vezes, somente aspectos gerenciais, conforme criticado por Mello et al. (2013). Nesse sentido, elementos contextuais, culturais e ideológicos, colocados à margem ao se tratar da abordagem da competência, podem enfatizar o aspecto instrumental em detrimento da dimensão contextual e dos saberes envolvidos.

$\mathrm{Na}$ fala dos participantes emergiu a questão do corporativismo na dinâmica da avaliação. O corporativismo também se propõe a contornar elementos da burocracia, contudo, assim o faz por meio da coletividade entre os membros da organização. Dessa forma, visa resistir às normas e prescrições, além de descaracterizar a competição entre os membros de uma organização pública (Secchi, 2009). O corporativismo é, de certa forma, relacionado à prática do "jeitinho", pois ambos buscam contornar alguma prática da burocracia. Entretanto, o "jeitinho" constitui uma prática informal e camarada de contornar elementos da burocracia de maneira individualizada. Já o corporativismo aproxima-se do contorno de uma prática burocrática de forma coletiva, em que integrantes de um mesmo grupo social se associam para obtenção de vantagens pessoais comuns aos demais integrantes do grupo (Secchi, 2009).

A avaliação pode ser entendida como um elemento que compõe as RS de competência e compreende os seguintes aspectos: a avaliação como mensuração de competência, a avaliação como reconhecimento de competência e a avaliação como "jeitinho", corporativismo e formalismo. Assim, esses aspectos influenciam o pensamento social ancorando a avaliação por meio da experiência do grupo, na memória do "sempre foi assim", "vinte de cima em 
baixo [sic]" e na forma de se fazer a avaliação. A partir da memória, o objeto é categorizado, rotulado e passa a ser representado no mundo exterior pelos sujeitos, remodela comportamentos, valores e sentidos que são construídos no grupo, conforme descrito por Arruda (2014). Nesse sentido, a prática da avaliação na organização de acordo com os grupos acontece por meio da experiência no sentido de "faz-se desta forma" ou "sempre foi assim", influenciando as práticas e a formação das RS sobre competência entre os envolvidos.

\section{Contexto}

A Classe 2, "Contexto", sinalizou o cenário organizacional em que os profissionais realizam suas atividades e em que vislumbram e vivenciam no cotidiano da organização. Esta classe teve $19 \%$ de representatividade e caraterizou o contexto na organização, que se encontra em um movimento de mudança.

Quadro 3 - UCE da Classe "Contexto"

\begin{tabular}{|c|c|}
\hline Trechos de UCE & Tópicos do mundo lexical \\
\hline $\begin{array}{l}\text { "A gente tem uma (história) de (mais) de cem [anos], mas nascendo agora. Então, que (instituição) é (essa) } \\
\text { que eu estou fazendo parte? A gente tem (um) choque de geração muito (grande), porque tem a (galera) } \\
\text { (dos) (concurseiros), tem (o) menininho que é (o) primeiro (emprego) dele, tem esse (monte) de coisas, e } \\
\text { tem uma geração (mais) (antiga)" Damares, Gestor. } \\
\text { "Então (passa) muito (por) (isso) da gente (aceitar) que isso aqui está (mudando). A gente que (estudou) } \\
\text { na (escola) já (traz) uma bagagem, (ai) eu falo (do) (amor), da gratidão (pela) (instituição), (pelo) o que a } \\
\text { gente conseguiu, (pelas) pessoas que somos" Josafá, Gestor. }\end{array}$ & (Re)construção identitária \\
\hline $\begin{array}{l}\text { "Dadas as suas (necessidades) que a gente (pede), mas ele é (bom) [plano de carreira], mas principalmente } \\
\text { (pelo) (incentivo). Eu vou ter (um) (incentivo) (para) (estudar), eu vou ser (liberado) (para) me afastar (para) } \\
\text { (mestrado) e (doutorado)" Salomé, Alfa. }\end{array}$ & \multirow[b]{2}{*}{$\begin{array}{l}\text { Elementos facilitadores ao } \\
\text { desenvolvimento na carreira }\end{array}$} \\
\hline $\begin{array}{l}\text { "Como diz, tem (até) (a) expressão, (só) se a pessoa é (o) subnitrato da flatulência (do) cocô de lagartixa } \\
\text { (ai) (manda) a pessoa embora. Eu acho que aqui tem (um) (diferencial) muito (grande). Não sei se (teria) } \\
\text { (também) (em) outras (instituições) de (ensino), mas aqui (no) [nome da instituição] eu percebo (um) } \\
\text { (incentivo) muito (grande) a (qualificação) das pessoas, (grande) mesmo, (incentivo) e tudo (mais), } \\
\text { (liberação)" Felipe, Alfa. }\end{array}$ & \\
\hline $\begin{array}{l}\text { "Se você for (comparar) (o) requisito de (ensino médio) com o (salário) que é, nossa (pelo) (mercado) é } \\
\text { (muito) (bom), é (excelente), é (maravilhoso). Só que a gente não (recebe) (no) (concurso) (um) (menino) } \\
\text { de (ensino médio). A gente (recebe) pessoas com outras formações" Damares, Gestor. }\end{array}$ & \multirow{2}{*}{$\begin{array}{l}\text { Elementos dificultadores ao } \\
\text { desenvolvimento na carreira }\end{array}$} \\
\hline $\begin{array}{l}\text { "E eu não (consegui) [liberação]. Eu (cheguei) ao ponto de pensar que eu talvez (tivesse) que desistir (do) } \\
\text { (mestrado) porque é (praticamente) impossível. E muita coisa nova acontecendo. E a solução que eu (vi) } \\
\text { foi (pedir) a redução de (jornada), quer dizer" Lia, GF Beta. }\end{array}$ & \\
\hline $\begin{array}{l}\text { "Então, eu trabalhei na iniciativa privada e (os) processos de seleção das (empresas), cada uma faz (do) } \\
\text { seu jeito, mas são (mais) rigorosas. Aqui a pessoa (provou) que ela sabe fazer a (prova) de (concurso) ela } \\
\text { (passou) e ela (veio para cá)" Josafá, Gestor. }\end{array}$ & \multirow{2}{*}{$\begin{array}{c}\text { A organização pública versus a } \\
\text { organização privada no processo } \\
\text { seletivo }\end{array}$} \\
\hline $\begin{array}{l}\text { "A (empresa privada) ela avalia suas habilidades. Você tem habilidade (para) isso, então você tem } \\
\text { competência, você trabalha aqui. Aqui não, é independente. Você fez uma (prova) e (passou), depende } \\
\text { (do) seu grau de (estudo)" Gideão, Gestor. }\end{array}$ & \\
\hline
\end{tabular}

Fonte: Alceste. Adaptado pelos autores.

Nota: Entre parênteses estão as palavras que formam a classe de palavras fornecida pelo software Alceste. Entre colchetes estão as palavras incluídas no processo de transcrição.

Constata-se nas falas dos gestores, o elo afetivo que os sujeitos relatam ter com a instituição, em virtude de experiências anteriores na organização. Tal fato influencia a formação das RS para esses sujeitos, pois, de acordo com Jodelet (2001), as RS são orientadas pela articulação de elementos afetivos, do contexto sócio-históricocultural, da dimensão cognitiva e da vivência social dos sujeitos. Embora a IFE tenha passado por um processo de reconfiguração institucional, em virtude de mudanças no campo da política educacional brasileira, para a categoria dos gestores a organização é designada como uma instituição centenária.

Os dados indicam que a realidade social vivida pelos participantes apresenta nuanças que remetem à bagagem de conhecimento adquirida, aspectos relacionados às práticas de gestão adotadas em cada grupo e o histórico vivenciado por estas pessoas, cada qual, trazendo consigo particularidades que conjuntamente compõem a realidade vivenciada, conforme destaca Jodelet (2001). Em relação às experiências vividas, elas apontam demasiadamente sua influência sobre a realidade dos sujeitos na organização, que trazem comparações e observações de outras realidades vivenciadas.

As RS de competência, para os profissionais da unidade central de administração da instituição Ômega, compreendem expressões socializadas que simbolizam atos, situações comuns e emergem no contexto social em que o cotidiano e as interações entre sujeitos e grupos influenciam o comportamento e o pensamento social. Sendo assim, as inserções sociais, as experiências vivenciadas, a memória, os valores, as crenças e as relações entre grupos, interferem na tomada de posição dos atores sociais, bem como no processo de formação das RS (Mendonça \& Lima, 2014; Doise, 2014; 2010).

A análise das falas contidas no mundo lexical da categoria "Contexto" indica outros elementos que compõem as representações sociais de competência, como o desenvolvimento pessoal e profissional, o crescimento na carreira, o incentivo da organização para o desenvolvimento profissional, a adequação das pessoas ao cargo, entre outros. Dessa forma, o pensamento social presente nos grupos possui uma estrutura complexa, com diversos elementos. Observa-se também que, em alguns momentos, os gestores e técnicos administrativos possuem pensamentos e posicionamentos diferenciados entre si sobre os diferentes elementos identificados.

A organização da RS de competência está ancorada na partilha de crenças e de experiências passadas (Trindade, Santos \& Almeida, 2014; Doise, 2014). Outro fator que contribui para a formação da RS de competência é a questão da memória. $\mathrm{Na}$ presente pesquisa pode-se verificar a relevância da memória em relação ao tempo em que alguns gestores estudaram na instituição Ômega, como também as experiências que os sujeitos trazem em 
virtude de terem trabalhado em organizações privadas. Assim, verifica-se que a partilha de crenças entre os profissionais técnicos administrativos e gestores, a diferenciação entre os indivíduos e grupos em relação aos objetos de representação e os posicionamentos dos indivíduos e grupos influenciam o pensamento social dos profissionais técnicos administrativos e gestores, ou seja, as RS de competências dos participantes estão ancoradas nas normas, nos valores e nos afetos aprendidos e compartilhados no cotidiano da vida (Doise, 2010).

\section{Competência como CHA e Inteligência Prática}

A Classe "Competência e Pessoas" demarcou $43 \%$ do conjunto das UCE, sendo o enunciado mais bem representado no conjunto dos resultados. Observaram-se os elementos comportamentais de competência, principalmente, no prisma dos gestores.

Quadro 4 - UCE da Classe "Competência e Pessoas"

\begin{tabular}{|c|c|}
\hline Trechos de UCE & $\begin{array}{l}\text { Tópicos do mundo } \\
\text { lexical }\end{array}$ \\
\hline $\begin{array}{l}\text { "Competência técnica (para) (nossa) equipe, (bem) (como) na (dele), é muito fácil. Então eu vou (mais) (pela) questão (da) } \\
\text { (interpessoalidade) desses relacionamentos. Eu não tenho problema como (Josafá) (tem). Eu não tenho problema. Enfim. } \\
\text { Não que eu esteja (no) (paraíso)” Eli, Gestor. }\end{array}$ & \multirow{2}{*}{$\begin{array}{l}\text { Desafios nas } \\
\text { relações } \\
\text { interpessoais }\end{array}$} \\
\hline $\begin{array}{l}\text { "É muito difícil você trabalhar com pessoas. Você (colocar) (um) (software), você desenvolver (um) (software) que é (aquela) } \\
\text { coisa (ali), que (no) (final) das (contas) é (quadrada), toda (certinha), (milimétrica), que você consegue fazer e entregar" Josafá, } \\
\text { Gestor. }\end{array}$ & \\
\hline $\begin{array}{l}\text { "Eu acho que a gente (tem) trabalhado, buscado muito isso. (Tem) (tido) (frutos) interessantes, (mas) você precisa o tempo } \\
\text { inteiro (reunir) (forças) e vem gente, vamos fazer, vamos, estamos (juntos) aqui, vem", Damares, Gestor. }\end{array}$ & \multirow{2}{*}{$\begin{array}{l}\text { Desafios na } \\
\text { mobilização de } \\
\text { pessoas }\end{array}$} \\
\hline $\begin{array}{l}\text { "(E) eu (cheguei) (em) (um) ponto que eu falei: a técnica é muito fácil. (Agora), as relações, a (filosofia), como que você } \\
\text { (interage) com as pessoas, motivar as pessoas, isso é muito (mais) difícil"Eli, Gestor. }\end{array}$ & \\
\hline
\end{tabular}

Fonte: Alceste. Adaptado pelos autores.

Nota: Entre parênteses estão as palavras que formam a classe de palavras fornecida pelo software Alceste.

A Classe "Competência no Cotidiano" trouxe a competência no cotidiano de forma mais expressiva na visão dos técnicos administrativos. Essa classe representou $22 \%$ das falas classificadas do corpus e tem como raiz de destaque "compet+", que compreende as palavras competência, competências e competente.

Quadro 5 - UCE da Classe "Competência no Cotidiano" Trechos de UCE "Eu vejo como uma teia (de) (habilidades). (Competência) como (habilidades), como (atitudes), um (conjunto) (de)
(conhecimentos). Eu colocaria não formalmente, (mas) eu imagino que competências são (atitudes), (habilidades),
e as (habilidades) as mais diversas, e (conhecimento) não (necessariamente) (específico), (mas) geral para lidar com (determinadas) (atividades)" Eli, Gestor.

"Eu acho que (competência) é um aporte (de) (conhecimentos), (de) (habilidades) que você (tem) e saber (usar) (aquilo)" Josafá, Gestor.

"É a (habilidade) (de) (realizar) algo, (dentro) do que ele falou. Simplificando, você (tem) (habilidade) (pra) fazer (alguma) coisa, que (depende) (de) (formação), (de) (conhecimento) (de) vida, (de) tudo". Hermes, Beta.

"Na verdade a (competência) está (ligada) com as (habilidades) (da) pessoa e (conhecimentos) (de) trazer um (resultado) diante de uma (demanda)" Rufo, Gama.

"Eu concordo com você (Salomé). Acho que (existe) uma confusão (de) (competências) para (habilidades), (ou) (seja), se você não é (apto) a (executar) isso você não é (competente)" Gideão, Alfa.

"(Execução) (de) trabalho (de) (forma) satisfatória. Então depois você para (pra) (pensar), (mas) essa (palavra) pode ter outro significado também, que é a questão das (atribuições). Quando você fala: não é (da) (sua) (competência), não é (da) (sua) alçada. (Mas) agora, na (nossa) conversa, já fica a questão (da) (habilidade). Então você já relativiza (seus) (conceitos) (de) (competência)" Felipe, Alfa.

"É (desvio de função). É uma (atividade) que não é (dela). Às vezes também acontece o (contrário), o (nível $E^{3}$ ) que (executa) (atividades) que é fora das (atribuições) dele, (de) (assistente administrativo), a gente (tem) alguns casos" Gideão, Alfa.

"(Mas) a (legislação) (permite). Isso não é um (desvio de função), (ela) coloca isso; (essas) (atribuições) diferenciadas" Rebeca, Beta.

Tópicos do mundo lexical
Competência como o conjunto
"CHA"
Competência como entrega de
resultados
Ampliação do conceito de
competência
"algo a mais" como uma
prática inadequada
Competência como execução

Fonte: Alceste. Adaptado pelos autores.

Nota: Entre parênteses estão as palavras que formam a classe de palavras fornecida pelo software Alceste.

Este item compreende os elementos do mundo lexical que compõem as Classes 3 e 4, "Competência no Cotidiano" e "Competências e Pessoas", respectivamente. A Classe 3 remete para a competência como $\mathrm{CHA}$. Por outro lado, a Classe 4 remete a competência como inteligência prática.

O conjunto de conhecimentos, habilidades e atitudes conhecido como $\mathrm{CHA}$, oriundo da escola norte-americana de competência (Borgo, Bianco \& Colbari, 2013; Fleury \& Fleury, 2001), foi um elemento presente nas falas dos sujeitos da categoria gestores, especificamente na Classe 3. Ressalta-se, entretanto, que nessa classe foi predominante o conjunto discursivo da categoria dos profissionais técnicos administrativos. Sendo assim, competência indica a realização de alguma atividade, com o alcance de um resultado considerado satisfatório para a organização. Competência, neste sentido, está relacionada a resultados preestabelecidos na execução de determinada atividade (Fleury \& Fleury, 2001; Fischer, Dutra, Nakata, \& Ruas, 2008; Santos, 2011).

Destaca-se que a RS dos técnicos administrativos sobre competência está associada à execução de atividades, sendo a noção de competência, ancorada em padrões de desempenho a serem alcançados e pode remeter a ações, atitudes e conhecimentos que os trabalhadores devem empreender para 
demonstrarem resultados nas organizações, conforme exposto por Santos (2011).

O posicionamento dos sujeitos é influenciado provavelmente por enunciados voltados para a formação que tiveram durante seu histórico pessoal e profissional, podendo indicar a influência de um modo de pensar que tem como origem outros países, em especial os Estados Unidas da América, no sistema de educacional brasileiro (Nicolini, 2003; Caldas \& Alcadipani, 2012). Essa constatação pode indicar ainda a influência norte-americana nos cursos de formação voltados para os profissionais do serviço público, bem como nas políticas de gestão implementadas pelo governo brasileiro.

Além disso, observa-se que a competência também pode estar associada à ideia de realizar "algo a mais", o que significa realizar uma atividade que não está prescrita em um determinado cargo. As atividades realizadas por estes trabalhadores seguem um conjunto de prescrições definidas em regulamentos formais, conforme entendimento de Riggs (2010). Entretanto, o "algo a mais" que estes profissionais precisam oferecer para serem considerados competentes, pode remeter a uma prática não adequada denominada pelo grupo como desvio de função. Esse conjunto discursivo está ancorado na visão de que o trabalho prescrito pode não corresponder ao trabalho real e vice-versa, uma vez que o trabalho a ser executado pelo trabalhador é aquele que emerge nas situações de trabalho para que o funcionário possa ser considerado competente (Zarifian, 2011). Tal visão está claramente relacionada à corrente francesa de competência e, muito provavelmente, às demandas exigidas no cotidiano do trabalho e as restrições impostas pela burocracia.

A Classe "Competência e Pessoas" representou, em maior profundidade, aspectos ligados às relações interpessoais na organização e foi evidenciada pelas falas, em sua maioria, dos gestores. Essa classe sinalizou para o produzir sentido na realização de um trabalho, na mesma direção das relações interpessoais estabelecidas e que poderão favorecer o desempenho das competências. Sendo assim, os dados apontam que, pela ótica dos gestores, a competência é entendida como uma dinâmica estabelecida nas relações interpessoais, em uma dimensão de trabalho em grupo, dedicação e entrega do trabalhador, conforme propõe Le Boterf (2003).

Para os gestores, a RS de competência é compreendida pela execução de atividades, entrega e pela convivência dos trabalhadores no contexto organizacional da pesquisa. Dessa forma, competência está voltada para a ação prática do "sabermobilizar" em uma situação de trabalho, isto é, está para além de possuir conhecimentos ou capacidades, sendo então, a mobilização oportuna e satisfatória do trabalhador em uma situação de trabalho específica, conforme defende Le Boterf (2003). Nesse sentido, a competência se dá na ação, em situação real de trabalho, através da mobilização de capacidades (Fischer et al., 2008) e conhecimentos do trabalhador (Le Boterf, 2003) em uma situação que exige a inteligência prática (Zarifian, 2011).

É interessante observar que há um entrelaçamento da corrente norte-americana (McClelland, 1973; Boyatzis, 1982; Borgo, Bianco
\& Colbari, 2013) e da corrente francesa (Zarifian, 2001; Le Boterf, 2003) no conjunto discursivo dos participantes. Dessa forma, observa-se que os elementos que compõem a RS de competência estão relacionados à corrente norte-americana, como a questão do $\mathrm{CHA}$, e à corrente francesa, já que a entrega dos resultados por meio da mobilização dos recursos necessários (independente do cargo) é uma questão presente. Esses resultados são semelhantes aos encontrados por Martins-Silva et al. (2014).

A pesquisa de Martins-Silva et al. (2014), por ser de natureza quantitativa, não permitiu analisar a dinâmica intergrupal. Dessa forma, os dados aqui apresentados revelam que a RS de competência se alicerça em aspectos que remetem ao significado de competência para os grupos (gestores e técnicos administrativos), ora se aproximando, ora se distanciando.

Considerando o conjunto de dados analisados (avaliação, contexto, competência como $\mathrm{CHA}$ e competência como inteligência prática), depreende-se o processo de formação das RS de competência para os profissionais da unidade central da administração. Para tal processo, aspectos ligados aos quatro níveis de análise que integram a abordagem societal de Doise (2010) se fazem presentes. Nesse sentido, há a articulação do campo social com valores e entendimentos individuais, com as crenças, com as opiniões compartilhadas, bem como com os aspectos simbólicos, afetivos e posicionamentos que os sujeitos adotam nas relações sociais (Doise, 2010). Outra questão interessante é que a formação profissional não demonstrou ser determinante no delineamento das RS como aponta a pesquisa de Souza, Serafim, \& Dias, (2010). Possivelmente, isso ocorreu pelo fato dos respondentes formarem uma classe heterogênea de formação profissional. A inserção social na organização, em termos das atividades a serem desempenhadas (gestor $x$ técnico administrativo) e o tempo de permanência na instituição, entretanto, mostraram direcionar algumas diferenças na RS de competência, aspecto similar à pesquisa de Souza, Serafim \& Dias (2010).

O processo de construção das representações sociais de competência compreende, desse modo, aspectos que circulam os processos intraindividuais; interindividual; intergrupal e societal ou ideológico. No caso do elemento avaliação, por exemplo, ao se considerar posicionamentos diferentes dos membros entre os grupos, aproxima-se da abordagem intergrupal de Doise (2010). Dessa forma, o pertencimento dos indivíduos nos grupos molda a compreensão e o entendimento acerca dos objetos sociais, conforme destacam Mendonça e Lima (2014).

Neste estudo, os aspectos evidenciados na formação das representações sociais de competência foram de maior destaque nas esferas intergrupal e societal, o que não significa dizer que não contenham elementos das demais esferas. Como o estudo se deu a partir da interação de indivíduos nos grupos de pertença, o acesso a esses níveis pode ter sido influenciado pelo método adotado.

\section{Considerações Finais}

A proposta deste artigo foi compreender o processo de formação das RS de competência para um grupo de profissionais que atua na unidade central de administração de uma IFE. Mais 
especificamente, foi proposto investigar o seu processo de ancoragem. Tendo como guia a TRS, chegaram-se às três dimensões consideradas elementos constituintes da RS de competência: 1) a avaliação, 2) o contexto e 3) a competência como conjunto $\mathrm{CHA}$ e a competência como inteligência prática. $\mathrm{O}$ processo de ancoragem da RS de competência para os participantes passa necessariamente pela inserção em um determinado contexto histórico, social e cultural (que inclui as crenças, as normas e os valores), pela inserção nos grupos sociais, pela experiência, pelos afetos e pela memória.

Além de identificar as RS de competência, foi possível compreender diversos elementos que envolvem o processo de formação do pensamento social entre profissionais técnicos administrativos e gestores. A ancoragem da RS de competência perpassa pela concepção de burocracia (Kobal, Teixeira Filho, \& Aquino Cabral, 2012), pelo formalismo (Riggs, 2010) e pelo jeitinho (Bernardo, Shimada \& Ichikawa, 2015), mas também pela experiência e comparação com as diferentes organizações e até mesmo pela vivência nessa mesma organização em tempos distintos, e pela convivência cotidiana com o trabalho e as suas demandas.

Além disso, verificou-se que a formação da RS de competência entre os profissionais inseridos na instituição Ômega apresenta aspectos similares e diferenciados. Assim, um mesmo elemento de RS pode apresentar significados construídos por concepções preexistentes na memória social, por opiniões compartilhadas, por representações construídas e reconstruídas, decorrentes das experiências dos sujeitos, tanto experiências individuais quanto em suas relações sociais (Doise, 2010).

Em relação à gestão da instituição "Ômega", este estudo ressalta a necessidade premente de se refletir sobre a importação da prática gerencial, normalmente usada em empresas privadas, sendo inserida no contexto das organizações públicas. Se a importação dos modelos ocorresse apenas entre empresas privadas, já seria necessário observar as particularidades de cada organização. Porém, quando ela ocorre no contexto público, é ainda mais relevante analisar e considerar o contexto organizacional.

Ao se pensar sobre os aspectos de gestão, uma pontuação pode ser feita sobre a inserção de práticas gerenciais consideradas universais, como o caso do gerencialismo. A partir do entendimento de que uma organização é composta por atores sociais em interação, as histórias, memórias e as formas de pensar interferem nas práticas exercidas por esses atores no cotidiano organizacional, o que, na implantação de um modelo gerencialista, pode ser colocado à margem.

Assim, uma contribuição desta pesquisa abarca a importância de se buscar compreender o pensamento social circulante na organização, ao serem abordadas e implementadas mudanças nos processos de gestão. Direcionar, por exemplo, o olhar sobre a temática que envolve a atividade de trabalho, em relação ao que é pensado, vivenciado e realizado pelos atores nas organizações pode ser um caminho a ser acessado pela TRS.

Além disso, a contribuição deste trabalho reside na articulação do objeto de pesquisa, considerado novo e, portanto, em construção para um grupo social, que é a competência. Além disso, a pesquisa é considerada relevante por articular o campo da Psicologia Social com o dos Estudos Organizacionais, buscando trazer para esse último um novo olhar em relação às abordagens consideradas tradicionais.

Esta pesquisa apresenta algumas limitações, como a quantidade de participantes. Isso se deu por dois motivos: primeiro, a técnica de grupo focal requer um quantitativo máximo de participantes por sessão. Segundo, a necessidade de se efetuar a delimitação da pesquisa, que impossibilitou a ampliação para as demais instâncias da estrutura da unidade de administração da IFE analisada e para as diversas unidades que a compõem. Entretanto, tais limitações não interferiram na análise dos dados, tendo em vista que foram atendidas as recomendações relacionadas à técnica de grupos focais e ao software utilizado nesse processo.

Cumpre destacar que a interpretação não generaliza ou dimensiona todas as RS relacionadas de competência que circulam na instituição Ômega, tendo em vista que as RS que surgem na organização são mais heterogêneas e complexas do que a proposição deste estudo. É possível que o tipo de atividade desenvolvida pelos participantes (atividade-meio), possa ter contribuído com as RS identificadas. Assim, pesquisas que ampliem os grupos que compõem a instituição Ômega são recomendadas, como também estudos estendidos a outras organizações. Além disso, a realização de estudos a partir da TRS com a modificação dos procedimentos metodológicos para acessar mais peculiaridades pode favorecer frutíferas discussões, tendo em vista as subjetividades que perpassam as organizações e os trabalhadores nelas inseridos.

\section{Referências bibliográficas}

Arruda, A. (2014). Representações Sociais: dinâmicas e redes. In: A. M. O. Almeida; M. F. S. Santos, \& Z. A. Trindade (Orgs.). Teoria das representações sociais: 50 anos. Brasília: Technopolitik, 441-489.

Bernardo, P., Shimada, N. E., \& Ichikawa, E. Y. (2015). O Formalismo e o "Jeitinho" a Partir da Visão de Estratégias e Táticas de Michel de Certeau: Apontamentos Iniciais. Revista Gestão \& Conexões, Vitória, 4(1), 45-67.

Borgo, C. B., Bianco, M. F., \& Colbari, A. L. (2013). Competência e cooperação em uma empresa brasileira de mineração. Revista Economia \& Gestão, Minas Gerais, 13(33).

Boyatzis, R. E. (1982). The competent manager: a model for effective performance. New York: John Wiley \& Sons.

Burrell, G., \& Morgan, G. (2005). Two Dimensions: four paradigms. In: Sociological Paradigms and Organizational Analysis: Elements of the Sociology of Corporate Life. Aldershot: Ashgate, 21-37.

Cabecinhas, R. (2004). Representações sociais, relações intergrupais e cognição social. Paidéia, Ribeirão Preto, 14(28), 125-137.

Caldas, M. P., \& Alcadipani, R. (2012). Americanizing Brazilian Management. Critical perspectives on international business. 8(1), 37-55.

Camargo, B. V. (2005). Alceste: um programa informático de análise quantitativa de dados textuais. In: A. S. P. Moreira, B. V. Camargo, J. C. Jesuíno, \& S. M. Nóbrega (Orgs.). Perspectivas teórico-metodológicas em representações sociais. João Pessoa: UFPB, 511-539.

Cavalcante, P. \& Carvalho, P. (2017). Profissionalização da burocracia federal brasileira (1995-2014): avanços e dilemas. Revista de Administração Pública, Rio de Janeiro 51(1):1-26.

Civelli, F. F. (1997). New competences, new organizations in a developing world. Industrial and Commercial Training, 29(7), 226-229.

Conselho Nacional de Saúde (Brasil). Ministério da Saúde. Resolução oㅜ 466, de 12 de dezembro de 2012. Diário Oficial [da] República Federativa do Brasil, Brasília, 13. jun. 2013. Seção 1, 59-62.

Doise, W. (1982). L'explication en psychologie sociale. Paris: Presses Universitaires de France.

Doise, W. (2010). O retorno da sociedade à psicologia social. In: Simpósio Gênero E Psicologia Social [Versão eletrônica]. UNB, Brasília. Recuperado em 03 de abril de 2015, de 
http://www.technopolitik.com.br/downloads/files/B_AnaisSimposio_Genero_ e_PsiSocial2010.pdf.

Doise, W. (2014). Sistema e metassistema. In: A. M. de O. Almeida, M. de F. de S. Santos, \& Z. A. Trindade (Orgs.). Teoria das representações sociais: 50 anos. Brasília: Technopolitik, 163-210.

Dutra, J. S. (2001). Gestão por competência. Um modelo avançado para o gerenciamento de pessoas. São Paulo: Editora Gente.

Eicher, V., Emery, V., Maridor, M. Gilles, I., \& Bangerter, A. (2011). Social representations in psychology: a bibliometrical analysis. Papers on Social Representations, v. 20, 11.1-11.19.

Fischer, A. L., Dutra, J. S., Nakata, L. E., \& Ruas, R. L. (2008). Absorção do conceito de competência em gestão de pessoas: a percepção dos profissionais e as orientações adotadas pelas empresas. In: J. S. Dutra, M. T. L. Fleury, \& R. L. Ruas (Orgs). Competências: conceitos, métodos e experiências. São Paulo: Atlas, 31-50.

Fleury, M. T. L., \& Fleury, A. (2001). Construindo o conceito de competência. Revista de Administração Contemporânea, Curitiba, V.5, número especial, 183-196.

Franco, M. L. P. B. (2003). Análise de conteúdo. Brasília: Editora Plano, 2003. Gaskell, G. (2013). Entrevistas individuais e grupais. In: M. W. Bauer, \& G. Gaskell. Pesquisa qualitativa com texto, imagem e som. Rio de Janeiro: Vozes, 64-89.

Godoy, A. S., Antonello, C. S., Bido, D. S., \& Silva, D. (2009). O desenvolvimento das competências de alunos formandos do curso de Administração: um estudo de modelagem de equações estruturais. Revista de Administração, São Paulo, 44(3), 265-278.

Jodelet, D. (2001). Representações sociais: um domínio em expansão. In: 41. (Org.). As representações sociais. Rio de Janeiro: EdUERJ, 2001, 17-

Kobal, A. B., Teixeira Filho, M. C., \& de Aquino Cabral, A. C. (2012). Burocracia Brasileira: um Comparativo com os Países do BRIC. Administração Pública e Gestão Social, 4(3), 246-268.

Kronberger, N., \& Wagner, W. (2013). Palavras-chave em contexto: análise estatística de textos. In: M. W. Bauer, \& G. Gaskell (Org.). Pesquisa qualitativa com texto, imagem e som: um manual prático. Petrópolis: Vozes, 416-441.

Le Boterf, G. (2003). Desenvolvendo a competência dos profissionais. Porto Alegre: Artmed.

Lima, L. C. (2008). A Articulação "Themata-Fundos Tópicos": por uma Análise Pragmática da Linguagem. Psicologia: Teoria e Pesquisa, Brasília, 24(2), 243-246.

Martins-Silva, P. O., Silva Junior, A., Peroni, G. G. H., Medeiros, C. P., Vitória, N. O (2016). Teoria das representações sociais nos estudos organizacionais no Brasil: análise bibliométrica de 2001 à 2014. Cadernos EBAPE.BR, v. 14(4), 891-919, 2016.

Martins-Silva, P. O., Silva, V. C.; Souza, S. P., \& Silva Júnior, A. (2014). O que é competência para os administradores do CRA-ES? Uma análise sob a perspectiva da teoria das representações sociais. In: M. de F. Bianco (Org.). Competências e gestão: dialogando com o trabalho e decifrando suas conexões. Vitória: Proex/UFES, 139-175.

Mcclelland, D. C. (1973). Testing for competence rather than for "intelligence". American Psychologist, 1-14.

${ }^{1}$ A Lei n. 11.091, de 12 de janeiro de 2005, publicada no Diário Oficial da União de 13 de janeiro de 2005, dispõe sobre a estruturação do plano de carreira dos cargos técnico-administrativos em educação, no âmbito das Instituições Federais de Ensino vinculadas ao Ministério da Educação.

2 O Decreto n. ${ }^{\circ} 5.707$, de 23 de fevereiro de 2006, publicado no Diário Oficial da União de 24 de fevereiro de 2006, institui a Política e as Diretrizes para o
Mello, S. P. T. de, Silva, F. M. da, Torres, I. A. C., \& Martins, M. I. (2013). Os desafios da gestão pública: aspectos voltados à implantação da gestão por competências. In: F. M. da Silva (Org.). Gestão pública brasileira: caminhos percorridos, avanços alcançados e desafios a serem superados. Curitiba: Editora Prismas.

Mendonça, A. P., \& Lima, M. E. O. (2014). Representações sociais e cognição social. Psicologia e Saber Social, 3(2), 191-206.

Moscovici, S. (2015). Representações sociais: investigações em psicologia social. 11. Ed. Petrópolis, RJ: Vozes.

Nicolini, A. (2003). Qual será o futuro das fábricas de administradores? RAE, Rio de Janeiro, 43(2), 44-54.

Reed, M. (2014). Teorização organizacional: um campo historicamente contestado. In: S. R. Clegg, C. Hardy, \& W. R. Nord. Handbook de estudos organizacionais: modelos de análise e novas questões em estudos organizacionais. São Paulo: Atlas, 61-97.

Riggs, F. W. (2010). Trends in the comparative study of public administration. International Review of Administrative Sciences, 76(4), 750-760.

Ruas, R. L. (2005). Gestão por competências: uma contribuição à estratégia das organizações. In: R. L. Ruas, C. S. Antonello, \& L. H. Boff (Orgs.). Os novos horizontes da gestão: aprendizagem organizacional e competências. Porto Alegre: Bookman, 34-55.

Santana, G. A. S., Reis, A. O., Reis, M. C. T., \& Tavares, B. (2013). A representação social na interpretação de um sonho de cidade coletivamente construído. Administração Pública e Gestão Social, 5(1), 21-27.

Santos, A. P. dos. (2011). Conhecimentos, habilidades e atitudes: o conceito de competências no trabalho e seu uso no setor público. Revista do Serviço Público, Brasília, 62(4), 369-386.

Secchi, L. (2009). Modelos organizacionais e reformas da administração pública. Revista de Administração Pública, Rio de Janeiro, 43(2), 347-369.

Souza, W. J., Serafim, L. S., \& Dias, T. F. (2010). Representações sociais do papel de gestores de organizações não-governamentais. Organizações \& Sociedade, 17(53), 363-378.

Torres, J. P. (2015). A conjugalidade em recém-casados pela análise societal das representações sociais de Willem Doise. Dissertação de mestrado, Universidade Federal do Espírito Santo, Vitória, 2015.

Trindade, Z. A., \& Enumo, S. R. F. (2001). Representações sociais de infertilidade feminina entre mulheres casadas e solteiras. Psicologia, saúde \& doenças, 2(2), 5-26.

Trindade, Z. A., Santos, M. de F. de S., \& Almeida, A. M. de O. (2014). Ancoragem: notas sobre consensos e dissensos. In: A. M. de O. Almeida, M. de F. S. Santos, \& Z. A. Trindade (Orgs.). Teoria das representações sociais: 50 anos. Brasília: Technopolitik, 133-162.

Winterton, J., \& Winterton, R (1999). Developing managerial competence. London: Routledge.

Zago, C. C., \& Retour, D. (2013). Cultura organizacional: nível coletivo constitutivo da gestão por competências. Gestão e Produção, São Carlos, 20(1), 180-191.

Zarifian, P. (2011). Objetivo competência: por uma nova lógica. São Paulo: Atlas

Desenvolvimento de Pessoal da administração pública federal direta, autárquica e fundacional.

${ }^{3}$ Nível E corresponde a uma terminologia da legislação que contempla os cargos cuja exigência para ingresso na carreira em formação de nível superior específico de graduação. 